\title{
Risk Factors and Clinical Features of Recurrent Benign Paroxysmal Positional Vertigo
}

\author{
Moo Keon Kim, Hee Ryung Kim, Hyun Woong Jun, \\ Ha Young Byun, Jae Ho Chung, and Seung Hwan Lee \\ Department of Otorhinolaryngology-Head and Neck Surgery, Hanyang University College of Medicine, Seoul, Korea
}

\section{재발성 양성 돌발성 체위성 현훈의 위험인자와 임상적 특성}

김무건 · 김희령 · 전현웅 · 변하영 · 정재호 · 이승환

한양대학교 의과대학 이비인후-두경부외과학교실

Received May 17, 2019

Revised July 2, 2019

Accepted July 9, 2019

Address for correspondence

Seung Hwan Lee, MD, PhD

Department of Otorhinolaryngology-

Head and Neck Surgery,

Hanyang University

College of Medicine,

222 Wangsimni-ro, Seongdong-gu,

Seoul 04763, Korea

Tel $+82-31-560-2368$

Fax $+82-31-566-4884$

E-mail shleemd@hanyang.ac.kr
Background and Objectives Benign paroxysmal positional vertigo (BPPV) is treated with appropriate canalith repositioning procedures, which are very effective for the treatment of BPPV. Nevertheless, the recurrence of BPPV may occur after the initial successful treatment. The purpose of this study was to investigate the risk factors and clinical features of recurrent BPPV.

Subjects and Method The retrospective study was performed for 227 patients who were diagnosed with BPPV and treated with appropriate canalith repositioning procedures from March 2013 to December 2014. We analyzed various clinical characteristics, locations and types of canalith for the whole BPPV patients, and the interval and frequency of recurrence in the patients of recurrent BPPV.

Results Of the total of 227 BPPV patients, 47 patients were recurrent BPPV (21\%). The patients of recurrent BPPV were significantly older than those of non-recurrent BPPV $(p=0.034)$. BPPV patients recurred more with increased age, with the significantly increased frequency of recurrence $(p=0.010)$. Twenty two patients were posterior semicircular canal canalolithiasis (PSCC) (46.8\%) and 25 patients were lateral semicircular canal canalolithiasis (LSCC) (53.2\%). The number of canalith repositioning procedures was significantly higher in LSCC patients than in PSCC patients $(p=0.041)$. The location change of affected canal were identified for 23 patients and the type change of LSCC to ipsilateral PSCC was the most common. Conclusion Age is an important prognostic factor to be considered in BPPV recurrence. Also, the affected semicircular canals were frequently changed in the recurrent BPPV. Korean J Otorhinolaryngol-Head Neck Surg 2019;62(10):562-7

Key Words Age factors · Benign paroxysmal positional vertigo $\cdot$ Risk factors.

\section{서 론}

양성발작성두위현훈(benign paroxysmal positional vertigo, BPPV)은 이석이 난형낭에서 탈락되어 반고리관으로 이

This is an Open Access article distributed under the terms of the Creative Commons Attribution Non-Commercial License (https://creativecommons.org/licenses/by-nc/4.0) which permits unrestricted non-commercial use, distribution, and reproduction in any medium, provided the original work is properly cited.
동하게 되어 두위 변화 시 심한 어지럼증을 동반하는 질환으 로 어지럼증의 원인 중 17 42\%에서 진단되는 단일 질환으로 는 가장 흔한 질환이다. ${ }^{1)}$ 대부분의 BPPV 는 원발성으로 발생 하지만 7 17\%의 경우는 외상, 내이염, 편두통, 메니에르씨병 등에 의해 유발될 수 있고 동시에 이러한 환자들에서 $\mathrm{BPPV}$ 재발의 가능성이 증가하게 된다. ${ }^{1-4)}$

BPPV에 대한 기록은 1921년 Bárány에 의해 처음 기술 되 
었다. 이후 1952년 Dix와 Hallpike는 BPPV 안진의 유발체 위법에 대해 기술하였고 $\mathrm{BPPV}$ 를 이석기관의 병변으로 추측 하였다. BPPV에 대한 치료법에 대해서도 지속적으로 연구되 어 1980년 Brandt와 Daroff ${ }^{6}$ 에 의해 후반고리관 결석의 치 료에 대해 처음 기술되었고, 1988년 Semont 등ㄱㅇㅔ 의해 liberatory maneuver가, 1992년 Epley ${ }^{8)}$ 에 의해 canalith repositioning maneuver가 후반고리관 결석의 치료로 소개되었다. 측반고리관 결석에 대한 치료는 1993년 Baloh, 1994년 Lempert, 1997년 Vannucchi와 1998년 Gufoni에 의해 소개되었으 며 상반고리관 결석에 대한 치료는 1997년 Herdman에 의해 소개되었다. ${ }^{9-13)}$

2008년 미국 이비인후과학회 진료지침에 의하면 후반고리 관 결석은 Dix-Hallpike 검사에서, 측반고리관 결석은 머리회 전 검사에서 안진이 유발되면 진단을 내리게 되며, 후반고리 관결석의 정복술로는 변형 Epley법과 Semont법이 추천되고, 측반고리관 결석의 정복술로는 Lempert법(바베큐 회전법)이 추천된다. ${ }^{1,14}$

이러한 BPPV의 이석정복술의 성공률은 다양하게 보고되는 데 후반고리관 결석에 대한 변형 Epley법의 경우 57 100\%, 측반고리관 결석에 대한 바베큐 회전법의 경우 60 98\%로 매 우 높은 성공률을 보이는 것으로 알려져 있다. ${ }^{15)}$

그럼에도 불구하고 $\mathrm{BPPV}$ 의 재발율은 평균적으로 약 $15 \%$ 정도로 보고되며, 연구자에 따라 5 50\%로 다양하게 보고되 는데, 초기 치료 6개월 내에는 5 13.5\%, 1년 후에는 10 18\%, 5 년 이후에는 $37 \sim 50 \%$ 로 기간이 길어질수록 재발율이 높아 지고 5년 이후에는 $50 \%$ 정도의 높은 재발율을 보인다. ${ }^{1)}$

이에 본 연구에서는 BPPV 환자를 재발군과 비재발군으로 나누어 재발과 관련된 인자에 대해 알아보고, $\mathrm{BPPV}$ 재발의 임상적 특성에 대해 확인해 보고자 한다.

\section{대상 및 방법}

2013년 3월부터 2014년 12월까지 BPPV로 진단받고 이석정 복술을 받은 환자 227예를 대상으로 의무기록을 통해 $\mathrm{BPPV}$ 재발 여부에 따라 BPPV 재발군과 비재발군으로 나누어 두 환자군의 연령, 성별, 증상, 개인력, 기저 질환, 이석의 위치 및 종류, 이석정복술 횟수, 재발 간격, 재발 횟수, 재발군에서의 이석 위치 변화 등을 후향적으로 조사하여 비교 분석하였다. 본 연구는 본원 기관윤리심의위원회의 후향적 연구승인을 받았다(2019-06-028). 본 연구에서 BPPV의 재발은 본원 외 래에서 처음 $\mathrm{BPPV}$ 를 진단받고 일차 치료로 이석이 정복되어 이후 검사상 음성이 나온 환자에서 최소 1개월 이후에 $\mathrm{BPPV}$ 가 다시 진단된 경우로 정하였고, 같은 반고리관으로 재발한
경우뿐 아니라 다른 반고리관으로 재발한 경우도 포함시켰 다. 환자의 증상, 개인력, 기저질환 등은 환자의 진술을 토대 로 조사하였다.

$\mathrm{BPPV}$ 진단은 후반고리관 결석은 Dix-Hallpike 수기를 통 해, 측반고리관 결석은 head roll test를 통해 진단하였으며 비 디오 안진 검사상 $\mathrm{BPPV}$ 에 적합한 전형적인 안진이 확인된 경 우만 대상에 포함시켰다. 외상성 $\mathrm{BPPV}$ 인 경우, 전정 신경염 이 동반되어 정확한 진단이 어려운 경우와 중추신경계 질환 이 동반된 경우는 본 연구 대상에서 제외하였다.

대상 환자들은 후반고리관 결석의 경우 변형 Epley법을 이 용하여 치료하였고, 측반고리관 결석의 경우 반고리관결석 (canalolithiasis)은 바베큐 회전법으로 치료하였으며, 팽대부 릉정결석(cupulolithiasis)은 진동기를 유양돌기에 대어 이석 을 떨어뜨려 반고리관결석으로 전환시킨 후 바베큐 회전법으 로 치료하였다. 재발한 $\mathrm{BPPV}$ 의 경우에는 재발 횟수와 관계없 이 일차 치료와 동일하게 해당 반고리관에 적합한 이석정복 술을 시행하여 치료하였다.

$\mathrm{BPPV}$ 의 재발군에서 후반고리관 결석과 측반고리관 결석의 차이를 알아보기 위해 두 군으로 나누어 비교 분석하였고, 재 발군에서 발병한 반고리관의 변화에 대해서도 조사하였다.

통계분석은 SPSS version 21(IBM Corp., Armonk, NY, USA)를 이용하여 카이제곱검정, Fisher's exact test, T-검정 과 Spearman 상관분석을 사용하였으며, 통계학적 유의 수 준은 $95 \%$ 이상 $(p$ value< $<.05)$ 으로 하였다.

\section{결 과}

해당 기간 동안 $\mathrm{BPPV}$ 로 진단받고 이석정복술을 받은 연구 대상 환자 227명의 평균 연령은 54.9 세였으며, 남자 62 명, 여 자 165 명으로 여자 환자가 더 많았다. 증상 발생부터 진단까지 평균 기간은 6.2일이었고, 이환된 귀는 우측 116예, 좌측 109예 등으로 양측이 비슷한 양상으로 보였으며, 이환된 반고리관은 후반고리관 109예, 측반고리관 116예, 상반고리관 1예 등으로 후반고리관, 측반고리관에서의 이환율이 높았다(Table 1).

연구대상 환자 227예 중 $\mathrm{BPPV}$ 재발군은 47예, $\mathrm{BPPV}$ 비재 발군은 180 예로 $21 \%$ 의 재발율을 보였다. 두 군 간의 비교 분 석에서 평균연령은 재발군 58.5세, 비재발군 54.0세로 유의하 게 재발군에서 높은 것으로 확인되었다 $(p=0.034)$. 재발군에 서 만성중이염 과거력, 메니에르씨병 등 기타 귀 질환의 빈도 가 높았으나, 통계적으로 유의한 차이는 없었다 $(p=0.105, p=$ 0.207). 성별, 발병시기, 발병 반고리관, 초기 치료 이석정복술 횟수에 있어서도 두 군 간의 의미 있는 차이는 없었다. 또한 이환된 반고리관의 종류도 재발군과 비재발군에서 의미 있 
는 차이는 없었다(Table 1).

기저 질환 및 동반 증상과 재발 여부 간에는 유의한 차이 를 보이지 않았다.

$\mathrm{BPPV}$ 재발군 47예에서 재발 횟수는 평균 1.96회, 평균 재 발 간격은 8.87 개월이었고, 연령과 $\mathrm{BPPV}$ 재발 횟수 간의 상 관관계를 분석하였을 때, 연령이 증가할수록 $\mathrm{BPPV}$ 재발 횟 수가 유의하게 증가하는 양상을 보였다 $(p=0.010)$ (Fig. 1).

$\mathrm{BPPV}$ 재발군을 처음 $\mathrm{BPPV}$ 진단 당시 이환된 반고리관을 기준으로 후반고리관 결석군과 측반고리관 결석군으로 나누 어 비교 분석한 바 발병 시 치료를 위한 이석정복술 횟수에 있어서 후반고리관 결석군이 유의하게 적었고 $(p=0.041)$, 재발 횟수에 있어서는 후반고리관 결석군이 평균 2.36회로 평균 1.60 회인 측반고리관 결석에 비해 높은 재발률을 보였다 $(p=$ 0.049). 또한 연령, 성별, 발병시기, 평균 재발 간격 역시 이환 된 반고리관과는 상관없는 결과를 보였다(Table 2).

BPPV 재발군 47예 중 23예에서(48\%) 이석의 반고리관 위 치 변화를 보였고, 측반고리관 결석에서 동측의 후반고리관 결석으로 재발한 경우가 가장 많았다(Table 3).

\section{고 찰}

BPPV는 회전성 어지럼을 일으키는 말초성 내이 질환 중 가장 높은 빈도를 보이는 단일 질환으로 연령이 증가할수록

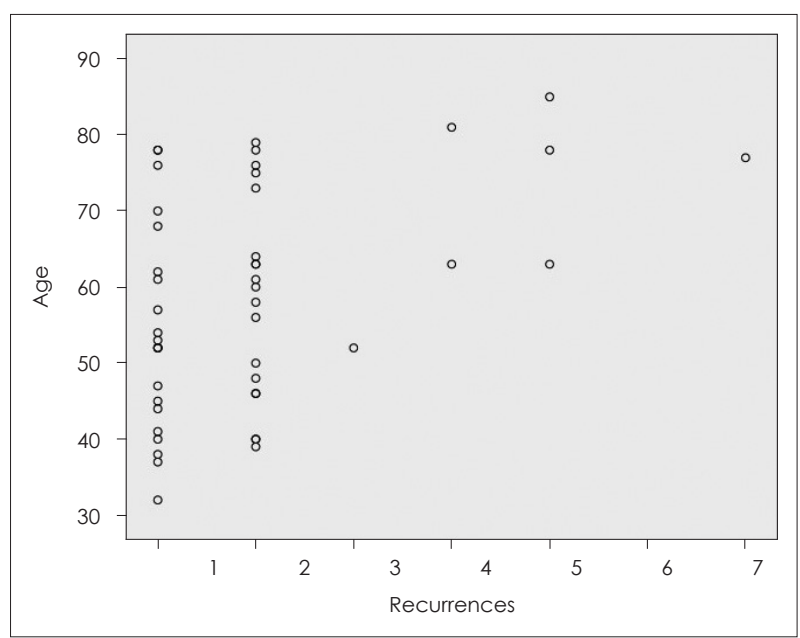

Fig. 1. Correlation between age and the number of recurrences. Spearman's correlation test $(\mathrm{rho}=0.373, p=0.010)$

Table 1. Demographics of benign paroxysmal positional vertigo patients

\begin{tabular}{|c|c|c|c|c|}
\hline Variable & Total & Recurrence $(n=47)$ & No recurrence $(n=180)$ & $p$-value \\
\hline Age (range) & $54.9 \pm 13.2$ & $58.5 \pm 14.4(32-85)$ & $54.0 \pm 12.8(18-83)$ & $0.034^{\dagger}$ \\
\hline Gender & & & & $0.669 \ddagger$ \\
\hline Male & 62 & 14 & 48 & \\
\hline Female & 165 & 33 & 132 & \\
\hline Onset (day) & $6.2 \pm 13.6$ & $6.5 \pm 13.2$ & $6.1 \pm 13.7$ & $0.845^{\dagger}$ \\
\hline Associated ear disease & 11 & 4 & 7 & \\
\hline COM & 6 & 3 & 3 & $0.105^{*}$ \\
\hline Sudden SNHL & 3 & 0 & 3 & $1.000^{*}$ \\
\hline SNHL & 1 & 0 & 1 & $1.000^{*}$ \\
\hline Meniere & 1 & 1 & 0 & $0.207^{*}$ \\
\hline Involved ear & & & & $0.330^{*}$ \\
\hline Right & 116 & 26 & 90 & \\
\hline Left & 109 & 20 & 89 & \\
\hline Both & 2 & 1 & 1 & \\
\hline Affected canal & & & & $0.918^{*}$ \\
\hline PSCC & 109 & 22 & 87 & \\
\hline LSCC & & & & $0.476 \neq$ \\
\hline Canalolithiasis & 67 & 16 & 51 & \\
\hline Cupulolithiasis & 49 & 9 & 40 & \\
\hline SSCC & 1 & 0 & 1 & \\
\hline Multiple & 1 & 0 & 1 & \\
\hline Numbers of CRM & $1.37 \pm 0.66$ & $1.47 \pm 0.62$ & $1.34 \pm 0.67$ & $0.255^{\dagger}$ \\
\hline Numbers of recurrence & & $1.96 \pm 1.33$ & - & \\
\hline Recurrence interval (month) & & $8.87 \pm 15.5$ & - & \\
\hline
\end{tabular}

The data are expressed as counts for categorical variables and as mean \pm standard deviations for continuous variables. *Fisher's exact test, tStudent t-test, ‡chi-square test. COM: chronic otitis media, SNHL: sensorineural hearing loss, PSCC: posterior semicircular canal, LSCC: lateral semicircular canal, SSCC: superior semicircular canal, CRM: canalith reposition maneuver 
Risk Factors of Recurrent Benign Paroxysmal Positional Vertigo I Kim MK, et al.

Table 2. Comparisons of recurred benign paroxysmal positional vertigo according to the initial diagnosis

\begin{tabular}{|c|c|c|c|}
\hline Variable & $\operatorname{PSCC}(n=22)$ & $\operatorname{LSCC}(n=25)$ & $p$-value \\
\hline Age (range) & $59.6 \pm 15.2(32-85)$ & $57.6 \pm 13.9(38-78)$ & $0.641^{\dagger}$ \\
\hline Gender & & & $0.321^{\ddagger}$ \\
\hline Male & 5 & 9 & \\
\hline Female & 17 & 16 & \\
\hline Onset (days) & $8.75 \pm 18.0$ & $4.67 \pm 6.9$ & $0.311^{\dagger}$ \\
\hline Involved ear & & & $0.238^{*}$ \\
\hline Right & 14 & 12 & \\
\hline Left & 7 & 13 & \\
\hline Both & 1 & 0 & \\
\hline Type & & & $0.002 \ddagger$ \\
\hline Canalolithiasis (\%) & $22(47.8)$ & $16(37.0)$ & \\
\hline Cupulolithiasis (\%) & - & $9(19.6)$ & \\
\hline Numbers of reduction & $1.27 \pm 0.55$ & $1.64 \pm 0.64$ & $0.041^{\dagger}$ \\
\hline Numbers of recurrence & $2.36 \pm 1.62$ & $1.60 \pm 0.91$ & $0.049+$ \\
\hline Recurrence Interval (months) & $12.36 \pm 20.85$ & $5.80 \pm 7.63$ & $0.149^{\dagger}$ \\
\hline Change of affected canal (\%) & $9(41)$ & $14(54)$ & $0.529 \ddagger$ \\
\hline Change of lesion side (\%) & $8(36)$ & $6(23)$ & $0.313^{\ddagger}$ \\
\hline
\end{tabular}

The data are expressed as counts for categorical variables and as mean \pm standard deviations for continuous variables. $*$ Fisher's exact test, †Student t-test, „chi-square test. PSCC: posterior semicircular canal, LSCC: lateral semicircular canal

Table 3. Types of canal change

\begin{tabular}{lc}
\hline \multicolumn{1}{c}{ Pathology } & Numbers $(\mathrm{n}=23, \%)$ \\
\hline LSCC $\rightarrow$ ipsilateral PSCC & $8(35)$ \\
PSCC $\rightarrow$ contralateral PSCC & $4(17)$ \\
LSCC $\rightarrow$ contralateral PSCC & $4(17)$ \\
PSCC $\rightarrow$ contralateral LSCC & $3(13)$ \\
PSCC $\rightarrow$ ipsilateral LSCC & $2(9)$ \\
LSCC $\rightarrow$ contralateral LSCC & $2(9)$ \\
\hline
\end{tabular}

LSCC: lateral semicircular canal, PSCC: posterior semicircular canal

발생빈도가 증가하여 노인 어지럼증 원인의 $50 \%$ 가 될 정도로 흔하다. ${ }^{14)}$ BPPV의 치료는 2017년 Bhattacharyya 등하에 의해 보고된 Clinical Practice Guideline에 따르면 초기 치료로 각 반고리관에 해당하는 이석정복술이 권고되며, 이석정복술 후의 움직임의 제한이나 전정 기능 억제 약물의 투여는 권고 되지 않는다. 그 외에 초기 치료 후 관찰을 하거나 전정 재활 치료를 하는 것이 치료로서 선택될 수 있으며, 후반고리관 폐 쇄술이나 전정 신경 절제술 등의 수술적 치료는 권고되지 않 는다. 또한 환자에 대한 교육이 중요한데, BPPV에 대해 환자 에게 안정을 시키고, 재발 가능성에 대해서 설명하며, 외래 재 방문의 중요성에 대해 설명을 해 주어야 한다. ${ }^{16)} \mathrm{BPPV}$ 는 후 반고리관과 측반고리관에 호발하게 되는데 후반고리관 결석 은 주로 변형 Epley법과 Semont법 등으로, 측반고리관 결석 은 바베큐 회전법, Gufoni법 등으로 정복하고 치료율은 매우 높게 보고되고 있다.1,16)

$\mathrm{BPPV}$ 는 높은 치료율에도 불구하고 재발율은 다양하게 보
고되고 있다. Choi 등 ${ }^{17)}$ 은 재발성 $\mathrm{BPPV}$ 가 총 120 예 중 15예 로 $12.5 \%$ 정도 된다고 보고 하였고, Pérez 등 ${ }^{18)}$ 은 $\mathrm{BPPV}$ 환자 69예를 대상으로 한 연구에서 재발율이 27\%라고 보고 하였 다. Nunez 등 19 은 BPPV의 평균 재발율을 $26.8 \%$ 로 보고하였 고, Kaplan-Meier 추정을 이용하여 40개월 후의 BPPV 재발 율이 약 $50 \%$ 정도 될 것으로 추정하였다. 각각의 보고에 따 라 초기 치료에서 완치부터 재발까지 1 주에서 1달까지 재발의 기준은 다양하였는데, ${ }^{17-19)}$ 이에 따라 재발율에 대한 결과의 차이가 있을 수 있다고 생각할 수 있다.

본 연구에서는 $\mathrm{BPPV}$ 재발율이 약 $21 \%$ 로 기존에 보고된 연구들에 비해 비교적 낮은 수치를 보이는데 이는 전형적인 안진이 확인된 경우만을 분석에 포함시키고, 통상적으로 재 발이 흔한 것으로 알려져 있는 외상에 의한 $\mathrm{BPPV}$ 를 제외하 였기 때문일 것이라 생각할 수 있다.

$\mathrm{BPPV}$ 의 재발의 원인이나 기전과 관련하여 많은 연구가 있 었으나, 재발의 기전은 확실히 알려진 바가 없다. BPPV 재발 과 전정미로염, 메니에르씨병, 돌발성 감각신경성 난청 등의 이과 질환이 연관성이 있다는 보고가 있었다. ${ }^{3,1720)}$ 이에 본 연 구에서도 귀 질환과의 연관성을 분석해 보았는데 이러한 기 존 연구 결과와 달리, 이번 연구에서는 내이 질환 및 중이 질 환과 BPPV 재발 간에는 유의한 관련성을 보이지 않았다 $(p>$ 0.05)(Table 1). 하지만 본 연구에서는 메니에르씨병과 같은 내 이 질환이 동반된 $\mathrm{BPPV}$ 의 증례가 많지 않아 이에 대해서는 추가 연구가 필요할 것이라 생각한다.

외상과 같은 외부요인이 없는 특발성 BPPV는 여자에게 비 
교적 많고 연령이 증가할수록 빈도가 높아지는 것으로 보고 되고 있다. ${ }^{14,17)}$ 재발성 $\mathrm{BPPV}$ 와 성별과의 연관성에 관한 연구 들이 있었는데, Brandt 등은 여자에서 58\%, 남자에서 39\%로 여자에서 유의하게 BPPV 재발율이 높았다고 보고한 반면, 다른 여러 연구에서는 BPPV 재발과 성별 간의 유의한 연관 성은 없다고 보고하였다.,18,21) 본 연구에서도 BPPV 재발과 성별 간의 유의한 연관성은 없었다.

$\mathrm{BPPV}$ 재발과 연령과의 연관성에 관해서 Brandt 등는 60 대 와 70대군을 비교하여 60대(68.5\%)가 70대(32.4\%)에 비해 재 발율이 높은 결과를 보고하였고, $\mathrm{Rashad}^{22)}$ 는 40 대 미만의 군에서 40 대 이상의 군보다 재발율이 낮다고 보고 하였으며, Pérez 등 ${ }^{18)}$ 은 연령과 BPPV 재발과는 연관성이 없다고 보고 하였다. 본 연구에서는 재발군과 비재발군을 비교하였을 때 연령은 유의하게 차이가 있었고 $(p=0.034)$, 재발군 내에서 연 령과 재발 횟수는 양의 상관관계를 보였다 $(p=0.010)$. 이를 통 해 노화는 $\mathrm{BPPV}$ 의 발병뿐 아니라 재발과도 밀접한 연관이 있을 것으로 생각된다.

$\mathrm{BPPV}$ 환자에서 이명, 난청, 두통 등의 다양한 증상이 동반 되었으나 재발 환자에서 유의하게 높게 나타난 증상은 없었 다. 본 연구에서 두통을 호소하는 환자가 많았는데 이와 관련 하여 재발성 BPPV가 편두통과 연관이 있을 수 있다고 언급 한 연구도 있어서, ${ }^{18)}$ 이에 대한 추가 연구가 필요하다.

또한 골다공증은 $\mathrm{BPPV}$ 발생에 영향을 미치는 것으로 알 려져 있는데, ${ }^{23)}$ 본 연구에서도 골다공증을 비롯한 고혈압, 당 뇨, 심장 질환, 갑상선 기능 저하증 등 기저 질환에 대해 조사 하였고, BPPV의 재발에 미치는 영향에 대해서는 통계적인 유 의성을 찾을 수 없었다.

$\mathrm{BPPV}$ 의 재발과 이환된 반고리관에 대한 연구에서는 이환 된 반고리관이 측반고리관인지 후반고리관인지에 따라서는 재발률의 차이는 없다는 보고가 있으나, ${ }^{17,18,24)}$ 상반고리관 결 석의 경우 다른 반고리관에 비해 재발율이 높다는 보고도 있 었다. ${ }^{18)}$ 본 연구에서는 다른 연구와 마찬가지로 후반고리관 결 석 환자과 측반고리관 결석 환자군에서 BPPV 재발률의 차 이는 없었다. 또한 다른 연구에서 다발성으로 반고리관 결석 이 생겼을 때 이석정복술 횟수가 유의하게 증가하였다는 보 고가 있었는데, ${ }^{18)}$ 본 연구에서는 다발성 반고리관 결석은 1 예 가 확인되었고 이석정복술 횟수는 3 회로, 평균인 1.5 회보다 많았다.

$\mathrm{BPPV}$ 재발군 내에서 연령과 재발 횟수 간에는 연령이 증 가할수록 재발 횟수가 증가하는 양의 상관관계를 보였는데 이를 바탕으로 연령과 $\mathrm{BPPV}$ 재발과의 연관성을 종합해 볼 때 노화가 $\mathrm{BPPV}$ 의 발병뿐 아니라 재발과도 밀접한 연관이 있으며 반복적으로 재발하는 빈도도 노화가 진행할수록 증
가한다는 것을 추정할 수 있다.

고령에서 생기는 BPPV는 발생기전이 정확히 밝혀지지 않 았으나 대부분 이석기관의 퇴행성 변화에 의해 발생하는 것 으로 추정된다. 이와 관련하여 Ross 등 ${ }^{25)}$ 은 사체연구를 통해 50 세 이상에서 구형낭반에 이석의 파괴가 잘 일어나고 연령 이 증가함에 따라 그 변성 정도가 더 심해진다고 보고하였고, Jang 등흔 돈 둥연구를 통해 노화에 따라 난형낭반에 특징 적으로 거대 이석이 관찰되고, 이석 연결 섬유의 약화나 끊어 짐이 보이며, 이석의 탈무기화와 연결 섬유의 절단에 의해 이 석조각이 발생하는 양상을 보여 $\mathrm{BPPV}$ 발생율을 높인다고 보 고 하였다. $\mathrm{Rhim}^{24}$ 은 연령에 따라 유병율이 증가하는 골다공 증, 고혈압, 고지혈증이 $\mathrm{BPPV}$ 의 주요 유발인자로 이러한 전 신적 상태는 이석의 대사장애에 영향을 주어 BPPV의 발생이 나 재발에 유발요인으로 작용하며, 특히 40세 이후 신체 노화 의 진행은 이석의 재발에 영향을 미친다고 보고하였다.

재발한 $\mathrm{BPPV}$ 환자를 대상으로 처음 진단 당시 이환된 반 고리관을 기준으로 후반고리관 결석군과 측반고리관 결석군 으로 나누어 비교하였을 때, 후반고리관 결석의 경우 측반고 리관 결석에 비해 재발 횟수가 높은 것으로 나타났으며, 후반 고리관 결석군에서 이석정복술 횟수가 유의하게 적었는데, 이는 재발한 $\mathrm{BPPV}$ 환자에서 후반고리관 결석이 더 치료가 용이하지만 재발을 더 잘하는 경향이 있다는 것을 의미한다 (Table 2). 반면 전체 BPPV 환자군을 대상으로 후반고리관 결 석군과 측반고리관 결석군을 나누어 이석정복술 횟수를 분석 하였을 때는 두 군 간 유의한 차이를 보이지 않았다 $(p>0.05)$.

본 연구에서는 재발한 $\mathrm{BPPV}$ 환자의 $48 \%$ 에서 이환된 반고 리관이 바뀌었으며, $30 \%$ 는 이환된 귀의 좌우 방향이 변했다. 이러한 변화는 첫 진단 시 이환된 반고리관에 상관없이 발생 하였으며, 이를 통해 재발하는 BPPV 역시 특정한 요인에 의 해 유발되는 것이 아니라 특발적으로 발생하는 것으로 생각 해 볼 수 있다. 기존 연구에서도 BPPV 재발 시 약 $68 \%$ 에서 반고리관 결석의 위치가 변했으며 $37 \%$ 에서 반대편의 반고리 관 결석으로의 재발을 보고하였으며, 본 연구의 결과와 유사 하였다. ${ }^{18)}$

재발성 $\mathrm{BPPV}$ 의 치료에 있어서 반복적인 이석정복술 외에 도 추가적인 적절한 치료와 상담이 이루어져야 한다. 재발 환 자의 $25 \%$ 정도에서 전정 기능 이상과 연관성을 보이므로 전 정 기능 검사가 필요하며 동반되는 전정 기능 이상이 있을 경 우 전정 재활 치료로 환자의 증상을 호전시켜 줄 수 있다.1,14,16)

또한 환자에게 $\mathrm{BPPV}$ 재발율과 재발의 위험성에 대해 인지 하도록 상담해 주는 것이 중요한데 이러한 상담은 환자의 재 발성 BPPV에 대한 빠른 인지를 통해 보다 신속한 치료가 이 루어질 수 있도록 도와주며 BPPV가 재발했을 때 환자의 걱 
정을 덜어주고 증상에 대한 영향을 줄이는 데 도움을 준다. ${ }^{1)}$

본 연구의 제한점은 내원 환자를 대상으로 의무기록 분석 으로 진행되어 완벽한 추적 관찰이 이루어지지 못하였을 가 능성이 있으며, 후향적인 연구 진행으로 인해 BPPV와 연관된 인자들에 대한 정보의 충실성에 대한 오류가 있을 수 있다. 또 한 재발과 연관된 인자가 나이밖에 확인되지 않아 여러 가지 인자들의 상호관계를 분석할 수 없었다.

본 연구에서 $\mathrm{BPPV}$ 환자에서 두통이 많았다는 점에서 $\mathrm{BPPV}$ 와 두통과의 연관성에 대한 연구를 추가적으로 해 볼 수 있 을 것으로 생각되며, 본 연구에서는 1 60개월 다양한 재발 기 간을 확인하였는데, 단기간에 재발한 $\mathrm{BPPV}$ 와 장기간에 걸 쳐서 재발한 $\mathrm{BPPV}$ 환자의 특성을 비교해 본다면 재발한 $\mathrm{BPPV}$ 의 특성을 이해하는 데 큰 도움이 될 것이다. 또한 재발 성 $\mathrm{BPPV}$ 군에서 결석의 위치 변화가 많았다는 점에서 이와 관련된 병태생리를 밝혀내는 것이 중요할 것이라 생각한다.

본 연구를 통해 재발한 $\mathrm{BPPV}$ 환자들이 재발하지 않는 $\mathrm{BPPV}$ 환자에 비해 연령이 유의하게 높고, 재발 횟수와 연령 이 양의 상관관계를 보임을 알 수 있었다. 하지만 재발에 특 이적인 기저 질환, 이과 질환, 동반 증상 등은 특정할 수 없 었다. 또한 재발한 $\mathrm{BPPV}$ 환자에서도 이환된 반고리관에 따 른 성별, 연령, 재발 간격 등에 대한 유의한 차이는 없었으나, $48 \%$ 에서 이환된 반고리관의 위치가 변하였다. 이 같은 결과 로 미루어 노화와 재발성 BPPV에 대한 추가 연구가 필요할 것으로 생각되며, BPPV의 재발은 특정한 요인에 의한 것보 다는 특발적으로 발생하는 것으로 생각해 볼 수 있다.

\section{ORCID}

Seung Hwan Lee ～https://orcid.org/0000-0003-2001-7689

\section{REFERENCES}

1) Bhattacharyya N, Baugh RF, Orvidas L, Barrs D, Bronston LJ, Cass $\mathrm{S}$, et al. Clinical practice guideline: Benign paroxysmal positional vertigo. Otolaryngol Head Neck Surg 2008;139(5 Suppl 4):S47-81.

2) Brandt T, Huppert D, Hecht J, Karch C, Strupp M. Benign paroxysmal positioning vertigo: A long-term follow-up (6-17 years) of 125 patients. Acta Otolaryngol 2006;126(2):160-3.

3) Tanimoto H, Doi K, Nishikawa T, Nibu K. Risk factors for recurrence of benign paroxysmal positional vertigo. J Otolaryngol Head Neck Surg 2008;37(6):832-5.

4) Sakaida M, Takeuchi K, Ishinaga H, Adachi M, Majima Y. Longterm outcome of benign paroxysmal positional vertigo. Neurology 2003;60(9):1532-4

5) Dix MR, Hallpike CS. The pathology symptomatology and diagnosis of certain common disorders of the vestibular system. Ann Otol Rhinol Laryngol 1952;61(4):987-1016.

6) Brandt T, Daroff RB. Physical therapy for benign paroxysmal positional vertigo. Arch Otolaryngol 1980;106(8):484-5.

7) Semont A, Freyss G, Vitte E. Curing the BPPV with a liberatory maneuver. Adv Otorhinolaryngol 1988;42:290-3.

8) Epley JM. The canalith repositioning procedure: For treatment of benign paroxysmal positional vertigo. Otolaryngol Head Neck Surg 1992;107(3):399-404

9) Baloh RW, Jacobson K, Honrubia V. Horizontal semicircular canal variant of benign positional vertigo. Neurology 1993;43(12):2542-9.

10) Lempert T. Horizontal benign positional vertigo. Neurology 1994; 44(11):2213-4.

11) Vannucchi P, Giannoni B, Pagnini P. Treatment of horizontal semicircular canal benign paroxysmal positional vertigo. J Vestib Res 1997;7(1):1-6.

12) Herdman SJ. Advances in the treatment of vestibular disorders. Phys Ther 1997;77(6):602-18.

13) van den Broek EM, van der Zaag-Loonen HJ, Bruintjes TD. Systematic review: Efficacy of Gufoni maneuver for treatment of lateral canal benign paroxysmal positional vertigo with geotropic nystagmus. Otolaryngol Head Neck Surg 2014;150(6):933-8.

14) Park HY. Guideline of benign paroxysmal positional vertigo by evidence-based medicine. Korean J Otorhinolaryngol-Head Neck Surg 2012;55(12):751-6.

15) Kim JH, Jung EJ, Song CE, Song MH, Park KC, Ko KM, et al. Risk factors for treatment failure in benign paroxysmal positional vertigo. Korean J Otorhinolaryngol-Head Neck Surg 2013;56(2):74-8.

16) Bhattacharyya N, Gubbels SP, Schwartz SR, Edlow JA, El-Kashlan $\mathrm{H}$, Fife $\mathrm{T}$, et al. Clinical practice guideline: Benign paroxysmal positional vertigo (update) executive summary. Otolaryngol Head Neck Surg 2017;156(3):403-16.

17) Choi SJ, Lee JB, Lim HJ, Park HY, Park K, In SM, et al. Clinical features of recurrent or persistent benign paroxysmal positional vertigo. Otolaryngol Head Neck Surg 2012;147(5):919-24.

18) Pérez P, Franco V, Cuesta P, Aldama P, Alvarez MJ, Méndez JC. Recurrence of benign paroxysmal positional vertigo. Otol Neurotol 2012;33(3):437-43.

19) Nunez RA, Cass SP, Furman JM. Short- and long-term outcomes of canalith repositioning for benign paroxysmal positional vertigo. Otolaryngol Head Neck Surg 2000;122(5):647-52.

20) Gross EM, Ress BD, Viirre ES, Nelson JR, Harris JP. Intractable benign paroxysmal positional vertigo in patients with Meniere's disease. Laryngoscope 2000;110(4):655-9.

21) Kansu L, Avci S, Yilmaz I, Ozluoglu LN. Long-term follow-up of patients with posterior canal benign paroxysmal positional vertigo. Acta Otolaryngol 2010;130(9):1009-12.

22) Rashad UM. Long-term follow up after Epley's manoeuvre in patients with benign paroxysmal positional vertigo. J Laryngol Otol 2009;123(1):69-74.

23) Vibert D, Kompis M, Häusler R. Benign paroxysmal positional vertigo in older women may be related to osteoporosis and osteopenia. Ann Otol Rhinol Laryngol 2003;112(10):885-9.

24) Rhim GI. Variables for one year recurrence of benign paroxysmal positional vertigo. Korean J Otorhinolaryngol-Head Neck Surg 2014;57(5):314-9.

25) Ross MD, Peacor D, Johnsson LG, Allard LF. Observations on normal and degenerating human otoconia. Ann Otol Rhinol Laryngol 1976;85(3 pt 1):310-26.

26) Jang YS, Hwang CH, Shin JY, Bae WY, Kang MK, Kim LS. Aging effect on the morphology of the otoconia using scanning electron microscopy. Korean J Otolaryngol-Head Neck Surg 2005;48(7): 841-7. 